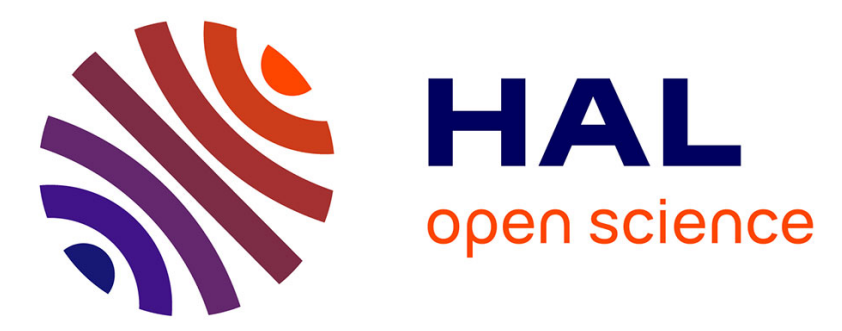

\title{
Study on Survey Methods for Crop Area Change Reasons at National Scale
}

Quan Wu, Hualang Hu, Yanxia Liu, Danqiong Wang, Xinyu Duan, Lijuan Jia, Yajuan He

\section{- To cite this version:}

Quan Wu, Hualang Hu, Yanxia Liu, Danqiong Wang, Xinyu Duan, et al.. Study on Survey Methods for Crop Area Change Reasons at National Scale. 8th International Conference on Computer and Computing Technologies in Agriculture (CCTA), Sep 2014, Beijing, China. pp.40-47, 10.1007/978-3319-19620-6_5 . hal-01420268

\section{HAL Id: hal-01420268 \\ https://hal.inria.fr/hal-01420268}

Submitted on 20 Dec 2016

HAL is a multi-disciplinary open access archive for the deposit and dissemination of scientific research documents, whether they are published or not. The documents may come from teaching and research institutions in France or abroad, or from public or private research centers.
L'archive ouverte pluridisciplinaire HAL, est destinée au dépôt et à la diffusion de documents scientifiques de niveau recherche, publiés ou non, émanant des établissements d'enseignement et de recherche français ou étrangers, des laboratoires publics ou privés. 


\title{
Study on Survey Methods for Crop Area Change Reasons at National Scale
}

\author{
Quan $\mathrm{Wu}^{1, \mathrm{a}}$, Hualang $\mathrm{Hu}^{1, \mathrm{~b}}$, Yanxia Liu ${ }^{2, \mathrm{c}}$, Danqiong Wang ${ }^{1, \mathrm{~d}}$, Xinyu Duan ${ }^{2, \mathrm{e}}$, \\ Lijuan Jia ${ }^{1, \mathrm{f}}$ Yajuan $\mathrm{He}^{1, \mathrm{~g}}$ \\ ${ }^{1}$ Remote Sensing Application Centre,Chinese Academy of Agricultural Engineering, \\ Beijing 100125,China; \\ ${ }^{2}$ Heilongjiang Academy of Agricultural Sciences,Harbin 150086, China \\ a'wuquan95@tom.com, landson_hu@sohu.com,,liuyanxia_2001@163.com,,1226773217@.qq.com
}

\begin{abstract}
Remote Sensing Application Centre (RSAC) has been working on monitoring the main crop planting areas as an operational task and a research project based on its system for several years. A problem has been proposed from the RSAC'S technology system, which is that the monitoring result is only an estimate to main crop planting areas without quantitative explanation to crop area change reasons. The study as a project approved by RSAC attempts to solve the problem. A survey index system about crop area change reasons has been established by questionnaire and expert consultation. Through further research, 9 driving factors of crop area change have been set up by assembling 5 survey indexes. Based on triangular whitenization weight function of grey system theory, the crop Area Change Driving Model (ACDM) was designed. The factor weights and factor grey classes were produced through expert consultation. Heilongjiang province as the experiment region and single cropping rice as the experiment crop were selected in this study. The experiment result produced by ACDM is consistent with the estimate produced in monitoring crop area by RSAC in 2013.
\end{abstract}

Keywords: Crop area, Crop area change, Survey index, Driving factor, Grey system, Whitenization weight function, Estimate, RS

\section{Introduction}

Crop area change is an important project paid much attention by governments in the world because it is closely related with food security. Sampling methods are widely used to estimate main crop area change by many countries and regions, such as US, China, EU, etc.[1][2][3]. Monitoring Agriculture with Remote Sensing (MARS) is a project facing Europe in order to obtain crop yield information constituted by European Union Committee[4]. It is a kind of three-stage sampling based on unsupervised classification with multitemporal RS data. In America, the prediction of total crop yield is acquired from crop acreage and crop yield per unit. The crop acreage data is mainly gotten by June Agricultural Survey(JAS). Two different sampling units used by JAS are area frame covering America and name list frame 
consisted of the names of registered farmers[4]. In China, the operating prediction of crop area change is mainly provided by RSAC[5]. RSAC adopts two methods to obtain the acreage of main crops such as wheat, corn, cotton, soybean, rice, etc.. One method is stratified sampling with RS and the other is ground random sampling using GPS[1][2]. RSAC has been working on monitoring the main crop area change as an operational task and a research project based on the complete organization system and the maturity of a technical system for several years. RSAC submits monitoring results to Ministry of Agriculture at prescribed time according to the crop monitoring calendar every year[6]. The monitoring results are only estimates for interannual variation of crop areas while the explanation for the reasons of crop area change is qualitative not quantitative[7][8]. At the same time, at the beginning of the year planting intent survey is done by relevant departments of the government in China, which is a kind of sampling survey to peasant households through the interview. Although the interannual variation of crop areas can be calculated based on data from investigated peasant households, there is not quantitative interpretation for the reasons of crop area change.

\section{Objectives}

It is the first objective of the research to theoretically establish a set of survey index system for crop area change reasons. Going a step further, the ultimate goal is to find driving factors of crop area change and set up the Area Change Driving Model (ACDM) for estimating the trend of crop area change based on the driving factors. So, the reasons of crop area change will be explained quantitatively.

\section{Materials and Methods}

The study was acted as a research project authorized by CAAE (Chinese Academy of Agricultural Engineering), launched by RSAC at the beginning of 2013. In order to achieve the research goal RSAC form a group to carry out the work through selecting a study region and a crop for experiment. The members of the group come from the team specialized in monitoring Agricultural condition in RSAC, which have rich experience in Agricultural survey.

\subsection{The study region and crop for experiment}

Taking into account the combination of research and operational task, Heilongjiang province acted as study region was selected and single cropping rice acted as experimental crop was chosen from several crops. RSAC monitors single cropping rice area of Heilongjiang every year. The monitoring result can be used to test the study result. The following figure shows the spatial distribution of single cropping rice of Heilongjiang province in 2010. 


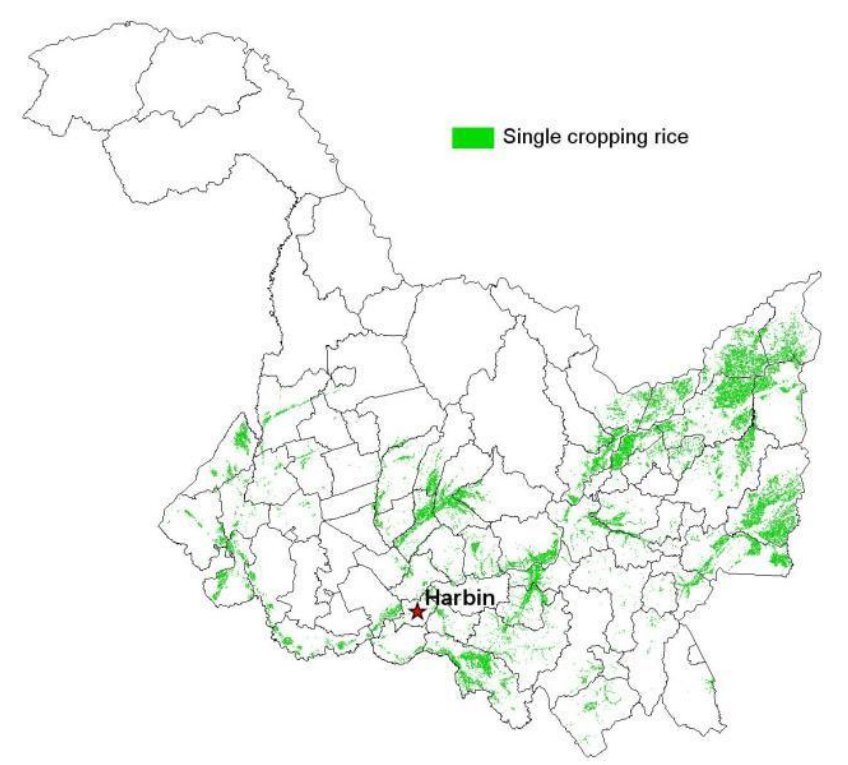

Fig. 1. The spatial distribution of single cropping rice of Heilongjiang province

\subsection{Candidate indexes for estimating the reasons of crop area change}

Because RSAC's operational system of crop area change monitoring has been working well for many years while the members of the study group are also main participants for monitoring task[5], the candidate indexes can be produced by the researchers based on rich experience to Agricultural survey. The indexes are the purchase price and sales revenue of main crops, production cost, natural disaster, field management, occupation of cultivated land, labor transfer, irrigation and water conservancy, Agricultural mechanization, tax and subsidy, planting structure adjustment, crop rotation, land transfer, product sales, etc..

\subsection{Survey indexes for estimating the reasons of crop area change}

When the candidate indexes were built, the next step is to extract survey indexes from them. The extraction rules are some characteristics about the indexes, which are integrity, importance, quantifiability and availability. How the job for extracting indexes was done? Based on analysis about the extraction rules to every index, the study group designed survey forms to investigate peasant household in the study region. There are 100 peasant households, distributed on 57 counties, which were surveyed. After this step, three survey indexes were picked up from 14 candidate indexes, which are production cost, yield, purchasing price. The indexes forming an index system can be classified into three categories, which are investment, production 
and yield. The process of extraction survey indexes from candidate indexes is shown below by figure 2 .

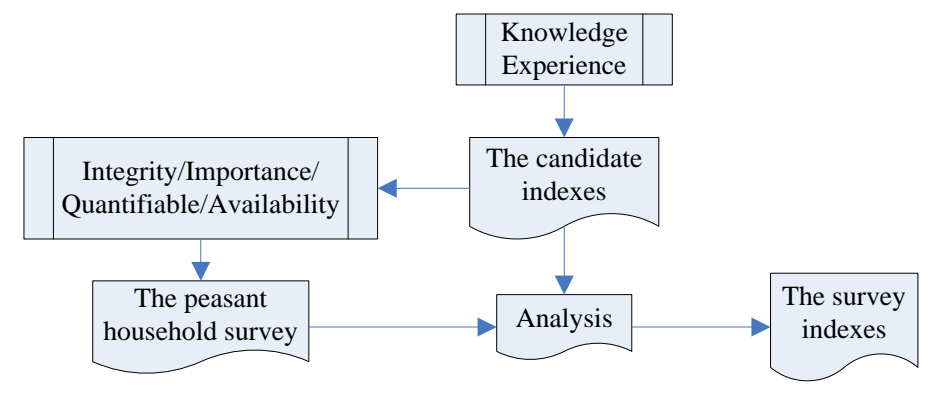

Fig. 2. The extraction flow of survey indexes from candidate indexes

\subsection{Driving factors for estimating crop area change}

The driving factors are the main contradiction of the existence and development of things. It determines the direction of the development of things. They are the index which have greater influence to interannual variation of crop area, or directly influence planting intentions of peasants. According to the survey indexes system mentioned above, the driving factors were produced based on further research. They are price difference, cost difference, and per unit yield difference, which are divided into 7 factors. The table 1 shows the situaton.

Table 1. Driving indexes for paddy area change in Heilongjiang province

\begin{tabular}{lcc}
\hline The driving factors & The meanings of driving factors & Marks \\
\hline Sale & $\begin{array}{c}\text { The difference of purchasing price of rice } \\
\text { between the current year with last year } \\
\text { The difference of purchasing price of rice } \\
\text { between the last year with the year before last } \\
\text { The difference between the purchasing price } \\
\text { of three year average to rice with the average } \\
\text { purchasing price of the main crops } \\
\text { The difference of production cost of rice } \\
\text { between the current year with last year } \\
\text { The difference of production cost of rice } \\
\text { between the last year with the year before last } \\
\text { The difference between the three year average } \\
\text { production cost of rice with the average } \\
\text { production cost of the main crops } \\
\text { The difference of rice yield between the } \\
\text { current year with last year }\end{array}$ & $\mathrm{X}_{1}$ \\
Yield & $\mathrm{X}_{2}$ & $\mathrm{X}_{4}$ \\
& $\mathrm{X}_{6}$ \\
\hline
\end{tabular}




\subsection{Crop Area Change Driving Model (ACDM)}

Uncertainty is usually due to internal and external disturbances and the level of human understanding to things. Probability statistics, fuzzy mathematics and grey system theory are the three most common types of uncertainty system research. Grey system theory focuses on the study of probability statistics and fuzzy mathematics to solve difficultly uncertain problems originated from the small sample and poor information[9]. Uncertainty phenomenon is more obvious in Agricultural production system. On the one hand, the grey information widely exists in the system. On the other hand, this "grey" information" is not easy to gain. The research on the reason of crop area change has obvious advantages through the application of grey system theory. This research adopts the method of grey clustering evaluation to establish a driving model of crop area change. Grey clustering includes grey relational clustering and grey whitenization weight function clustering. The grey whitenization weight function clustering includes grey fixed weight clustering, grey regulable weight clustering and whitenization weight function clustering based on endpoint or centre of triangle. The study adopts whitenization weight function clustering, based on triangular centre, acted as ACDM prototype. The general form of based on centre triangular whitenization weight function clustering is shown below.

$$
f_{j}^{k}(\bullet)=\left\{\begin{array}{l}
0, x \notin\left[\lambda_{j}^{k-1}, \lambda_{j}^{k+1}\right] \\
\frac{x-\lambda_{j}^{k-1}}{\lambda_{j}^{k}-\lambda_{j}^{k-1}}, x \in\left(\lambda_{j}^{k-1}, \lambda_{j}^{k}\right] \\
\frac{\lambda_{j}^{k+1}-x}{\lambda_{j}^{k+1}-\lambda_{J}^{k}}, x \in\left(\lambda_{j}^{k}, \lambda_{j}^{k+1}\right)
\end{array}\right.
$$

Where $j(j=1,2, \cdots, m)$ is survey index, $k(k=1,2, \cdots, s)$ is grey class, $\lambda(\lambda=1,2, \cdots, s)$ is the centre of grey class, $f_{j}^{k}(x)$ is the membership function belonging to grey class $k$ of observed value $x$ of index $j$. The Comprehensive clustering coefficient of object $i(i=1,2, \cdots, n)$ belonging to grey class $k$ is $\sigma_{i}^{k}$.

$$
\sigma_{i}^{k}=\sum_{j=1}^{m} f_{j}^{k}\left(x_{i j}\right) \bullet \eta_{j}
$$

Where $f_{j}^{k}\left(x_{i j}\right)$ is whitenization weight function of index $j$ belonging to $k$ subclass. $\eta_{j}$ is weight of $j$ index in comprehensive clustering. The formula of object $i$ belonging to $k$ grey class is shown below.

$$
\max _{1 \leq k \leq s}\left\{\sigma_{i}^{k}\right\}=\sigma_{i}^{k}
$$

Through expert consultation with experience, the weight of every driving factor and the grey class centre of every factor can be determined. 


\subsection{Experiment result}

The values of survey indexes. The surveyed crops are not only rice but other main crops which are soybean and corn acted as main crops in the region. Based on peasant household survey the average values of 3 survey indexes were gained. The data came from 3 years when there were not serious drought and snowstorm in this region from 2011 to 2013. This table shown below is presented the survey result to rice production region in study region.

Table 2. The survey result to main crops in Heilongjiang province

\begin{tabular}{lcccc}
\hline Crops & Years & Yield $(\mathrm{Kg} / \mathrm{mu})$ & Cost(Yuan/mu) & Purchase price(Yuan/50 Kg) \\
\hline \multirow{4}{*}{ Rice } & 2011 & 466.7 & 742.0 & 128.0 \\
& 2012 & 471.5 & 874.8 & 140.0 \\
& 2013 & 483.0 & 1031.4 & 150.0 \\
\multirow{4}{*}{ Soybean } & 2011 & 112.7 & 271.0 & 200.0 \\
& 2012 & 116.0 & 306.5 & 225.0 \\
& 2013 & 110.0 & 346.7 & 231.0 \\
\multirow{4}{*}{ Corn } & 2011 & 505.6 & 398.2 & 86.3 \\
& 2012 & 482.2 & 451.6 & 89.3 \\
& 2013 & 494.8 & 512.1 & 96.5 \\
\hline
\end{tabular}

The observed values and weights of driving factors. Using the data in the table 2 , it is easy to calculate the values of the driving factors for estimating rice area change. The seven driving factors were used to estimate rice area change with ACDM in 2013. The values of the seven driving factors are shown in table 3 . The weights of driving factors are obtained by expert investigation, which is also listed in table 3 .

Table 3. The survey values and weights of driving factors

\begin{tabular}{lccccccc}
\hline Driving factors & $\mathrm{X}_{1}$ & $\mathrm{X}_{2}$ & $\mathrm{X}_{3}$ & $\mathrm{X}_{4}$ & $\mathrm{X}_{5}$ & $\mathrm{X}_{6}$ & $\mathrm{X}_{7}$ \\
\hline The observed values & 10 & 12 & -15 & 157 & 133 & 502 & 12 \\
The weights & 0.20 & 0.15 & 0.10 & 0.20 & 0.15 & 0.10 & 0.10 \\
\hline
\end{tabular}

The grey class centres of 7 driving factors. In order to establish ACDM with the driving factors mentioned above based on its prototype, the first step is to determine the grey class centers of 7 driving factors. The result was gained through study and expert investigation, which is shown in table 4 below. Three grey classes on behalf of decreasing, unchanged and increasing situation of rice area from 2012 to 2013 were designed, whose centers are respectively marked by $\lambda_{1}, \lambda_{2}$ and $\lambda_{3}$. The $\lambda_{0}$ and $\lambda_{4}$ are centers of grey class continuation. 
Table 4. The grey class centers of driving factors

\begin{tabular}{cccccccc}
\hline Grey class centers & $\mathrm{X}_{1}$ & $\mathrm{X}_{2}$ & $\mathrm{X}_{3}$ & $\mathrm{X}_{4}$ & $\mathrm{X}_{5}$ & $\mathrm{X}_{6}$ & $\mathrm{X}_{7}$ \\
\hline$\lambda_{0}$ & -50 & -50 & -30 & 300 & 300 & 700 & -20 \\
$\lambda_{1}$ & -20 & -20 & -20 & 200 & 200 & 600 & -10 \\
$\lambda_{2}$ & 0 & 0 & -10 & 150 & 150 & 500 & 0 \\
$\lambda_{3}$ & 20 & 20 & 0 & 100 & 100 & 400 & 10 \\
$\lambda_{4}$ & 50 & 50 & 10 & 50 & 50 & 300 & 20 \\
\hline
\end{tabular}

Setting up ACDM. Using the values of grey class centers of every driving factor in table 4, the ACDM can be easily established based on its prototype presented by formula (1). Due to space limit, only the ACDM of the first and second driving factors is listed below.

$$
f_{1,2}^{1}(x)=\left\{\begin{array}{l}
0, x \notin[-50,0] \\
\frac{x+50}{30}, x \in(-50,-20] \\
\frac{-x}{20}, x \in(-20,0)
\end{array} \quad f_{1,2}^{2}(x)=\left\{\begin{array}{l}
0, x \notin[-20,20] \\
\frac{x+20}{20}, x \in(-20,0] \\
\frac{20-x}{20}, x \in(0,20)
\end{array} \quad f_{1,2}^{3}(x)=\left\{\begin{array}{l}
0, x \notin[0,50] \\
\frac{x}{20}, x \in(0,20] \\
\frac{50-x}{30}, x \in(20,50)
\end{array}\right.\right.\right.
$$

The grey clustering based on ACDM. When all ACDMs are finished, based on the models the next step is calculate the value of whitenization weight function of every driving factor with survey values in table 3, which are 3 figures presented 3 grey classes. When values of whitenization weight function of 7 driving factors, listed in table 5, are worked out, based on formula (2) the final step is calculate comprehensive coefficient with the weights of driving factors in table 3 . The result is shown in the last column in table 5.

Table 5. The comprehensive coefficient of each grey class

\begin{tabular}{ccccccccc}
\hline Grey classes & $\mathrm{X}_{1}$ & $\mathrm{X}_{2}$ & $\mathrm{X}_{3}$ & $\mathrm{X}_{4}$ & $\mathrm{X}_{5}$ & $\mathrm{X}_{6}$ & $\mathrm{X}_{7}$ & $\mathrm{X}$ \\
\hline 1 & 0.0000 & 0.0000 & 0.0500 & 0.0280 & 0.0000 & 0.0020 & 0.0000 & 0.0800 \\
2 & 0.1000 & 0.0600 & 0.0500 & 0.1720 & 0.0990 & 0.0980 & 0.0000 & 0.5790 \\
3 & 0.1000 & 0.0900 & 0.0000 & 0.0000 & 0.0510 & 0.0000 & 0.0800 & 0.3210 \\
\hline
\end{tabular}

\subsection{Analysis for the experiment result}

Using the formula (3), the result of the experiment is $\max _{1 \leq k \leq 3}\left\{\sigma_{1}^{k}\right\}=\sigma_{1}^{2}=0.5790$. This suggests that the rice area of study region from 2012 to 2013 is unchangeable. Because $\sigma_{1}^{2}=0.5790$ is close to $\sigma_{1}^{3}=0.3210$, it demonstrates the rice area has increasing trend. In 2013, the RSAC's monitoring result is that the rate of area change is $2.1 \%$, which confidence interval is from $-7.24 \%$ to $12.36 \%$ based on $95 \%$ degree of 
confidence. This shows the result of the experiment is consistent with the monitoring result produced by RSAC.

\section{Conclusion and problems}

Based on triangular whitenization weight function grey clustering can be used to establish ACDM. The model accurately reflects change situation of rice area from 2012 to 2013 in Heilongjiang province, Referencing RSAC' monitoring result. The survey indexes and driving factors founded in the study better reflect objective condition of reasons to rice area change, which better meet demands of the model.

Including survey indexes and driving factors, the ACDM prototype suits not only for rice but also for other main crops, such as winter wheat, soybean, corn, etc.. At the same time, the ACDM prototype suits not only for Heilongjiang province but also for other regions, such as northeast China, southwest China, etc.. Obviously, the parameters of the model designed in this study need to be recalculated because of different crops and different regions.

\section{Acknowledgement}

This paper is supported by the project named Study on survey methods for crop area change reasons at national scale, authorized by CAAE in 2012.

\section{References}

[1] Wu Quan, Sun Li. Sampling methods using RS and GPS in crops acreage monitoring at a national scale in China. Remote Sensing and Spatial Information Sciences, Beijing, 2008, Vol. XXXVII, Part B7, [WG VII/7]* : 1337-1342.

[2] Wu Quan, Sun Li, Wang Fei, Jia Shaorong. Theory of double sampling applied to main crops acreage monitoring at national scale based on $3 \mathrm{~S}$ in China. Computer and Computing Technologies in Agriculture IV, Part III, 2011, PP. 198-211.

[3] Wu Quan, Pei Zhiyuan, Wang Fei, Zhao Hu, Guo Lin, Sun Juanying, Jia Lijuan. A Sampling Design for Monitoring of the Cultivated Areas of Main Crops at National Scale Based 3S Technologies in China. Computer and Computing Technologies in Agriculture VI. Part II, IFIP 2013, AICT 393, pp. 10-19

[4] Yang Bangjie. Monitoring the agricultural condition using RS[M]. Beijing: China Agriculture Press, 2005, 19-29(in Chinese)

[5] Wu Quan, Sun Li, Wang Fei. The applications of 3S in operational monitoring system of main crops acreage in China. Computer and Computing Technologies in Agriculture - II , TSI Press, USA, 2010, Volume 24, pp. 319-324.

[6] Wu Quan, Pei Zhiyuan, Zhang Songling, Wang Fei, Wang Qingfa. The methods for monitoring land-use change with RS at non-large scale[M]. Beijing: China Agriculture Press, 2010, 33-40 (in Chinese) 
[7] Wu Quan, Sun Li, Wang Fei, Jia Shaorong. The Quantificational Evaluation of a Sampling Unit Error Derived from Main Crop Area Monitorings at National Scale Based 3S in China[J]. Sensor Lett. 2012, 10:213-220.

[8] Wu Quan,Pei Zhiyuan,Guo Lin,Liu Yuechen,Zhao Zhanying. A study of two methods for accuracy assessment to RS classification. Agro-Geoinformatics, 2012 First International Conference on. 2012, pp: 1-5.

[9] Liu Sifeng, Dang Yaoguo, Fang Zhigeng, Xie Naiming. Grey system theory and application[M]. Beijing: Science Press, 2010, 122-30(in Chinese) 